\title{
Risk Factors for Stroke in Rural Population of Telangana State of India, an Unmatched Case Control Study
}

\author{
Subhashini Prabhakar ${ }^{1}$ Sruthi Suravarapu ${ }^{2}$ Dilip Mathai ${ }^{3}$ Shivaiah Renangi ${ }^{2, \dagger}$ Sairam Challa ${ }^{2}$ \\ 1Department of Neurology, Apollo Hospitals, \\ Hyderabad, Telangana, India \\ 2Department of Community Medicine, Apollo Medical College, \\ Hyderabad, Telangana, India \\ ${ }^{3}$ Department of Medicine and Adult Infectious Diseases,

\begin{abstract}
Address for correspondence Sairam Challa, MBBS, MD, Department of Community Medicine, The Apollo Medical College, Apollo Health City, Jubilee Hills, Hyderabad 500033, Telangana, India (e-mail: srsairam_c@apolloimsr.edu.in).
\end{abstract}

Apollo Medical College, Hyderabad, Telangana, India

J Neurosci Rural Pract:2020;11:448-453

\begin{abstract}
Context Stroke tops the list of causes for acquired disability among adults and is the second leading cause of death worldwide. Evidence from developed countries indicate significant decline in stroke incidence and mortality, attributable to prevention of risk factors in general population. There is limited evidence on risk factors for stroke in rural India.

Aims This study aims to ascertain the risk factors for stroke in rural Telangana and provide a guide to health care providers in adopting treatment and prevention strategies.

Settings and Design The study was conducted in the Moinabad mandal of Ranga Reddy District, Telangana state of India. This is a population based unmatched case-control study.

Methods and Materials All the houses of Moinabad were approached by a door-to-door survey to identify cases. A total of 288 persons were enrolled in the study which included 144 cases and 144 controls.

Statistical Analysis To derive age and gender adjusted odds ratios of various risk factors, binary logistic regression analysis was performed.

Results The estimated crude prevalence of stroke in Moinabad mandal is 257 per lakh population. Modifiable risk factors identified were, total cholesterol, systolic blood pressure, alcohol consumption, smoking, diastolic blood pressure, low high-density lipoprotein cholesterol, and central obesity as measured by waist circumference.

Keywords

- case-control study

- risk factors

- stroke

Nonmodifiable risk factors identified were male gender and higher age group.

Conclusion The high prevalence of stroke in rural Telangana makes it an important public health challenge for the state. The identified risk factors need to be addressed at population level.
\end{abstract}

\section{Key Messages}

The health care providers including the National Program for Prevention and Control of Cancer, Diabetes, Cardiovascular Diseases and Stroke (NPCDCS) program officers should prioritize the identified risk factor for control of stroke in rural Telangana. The order of priority is high total cholesterol, systolic blood pressure,

†Passed away on June 6, 2019, before final manuscript was ready. alcohol consumption, smoking, diastolic blood pressure, low high-density lipoprotein (HDL) cholesterol, diabetes, and central obesity as measured by waist circumference.

\section{Introduction}

Stroke, or cerebrovascular accident, forms an important contributor to the global burden of diseases, leading the list of causes for adult acquired disabilities and death 
across the world..$^{1,2}$ A consequence of rapid epidemiological transition in India over past decades is a phenomenal rise in the occurrence of cardiovascular diseases including stroke. Recent estimate of stroke prevalence ranged widely among rural and urban population in India and has considerable regional differences. ${ }^{3,4}$ During the past decade four urban centers adopted WHO (World Health Organization) steps guidelines and undertook stroke surveillance studies to arrive at an estimate of stroke burden in their cities. There is insufficient information on stroke burden in rural India, where $70 \%$ of our population resides. Data from rural surveys on neurological disorders (including stroke) do not elucidate the actual stroke burden in this population. To our knowledge, there are only three studies that have examined this problem in rural India. One is from Kuthar valley Kashmir, ${ }^{5}$ the second is the Trivandrum stroke study ${ }^{6}$ which compared rural and urban population in Kerala, and the third examined stroke mortality in Gadchiroli district, Maharashtra. ${ }^{7}$ Studies focusing on cardiovascular risk factors in rural districts of erstwhile combined state of Andhra Pradesh (AP) and Karnataka reveal high prevalence of risk factors with more than $90 \%$ of adults having at least one modifiable cardiovascular risk factor and more than $15 \%$ at risk for MI or stroke in 10 years. ${ }^{8,9}$ Data from Trivandrum Stroke Registry also showed $90 \%$ of strokes had at least one modifiable risk factor, higher prevalence of risk factors, and 28-day poststroke mortality in rural subjects. ${ }^{6}$ Evaluation of local risk factors for stroke helps in developing policies specific to respective populations and achieve long-term gains in stroke control.

\section{Need for the Study}

Evidence from developed countries indicates significant fall in stroke burden attributable to secondary prevention strategies and prevention of risk factors (such as smoking) in the general population. Rural Andhra Pradesh data diverges from WHO Premise study which reveals a large urban to rural gap in knowledge of cardiovascular risk factors and use of medication for stroke prevention with less than $25 \%$ rural subjects using prescribed medication. ${ }^{9}$ The erstwhile combined state of Andhra Pradesh is now re-carved into states of Telangana and Andhra Pradesh. The proposed study will ascertain the risk factors for stroke in rural Telangana population and provide a guide to health care providers in adopting treatment and prevention strategies.

\section{Methodology}

\section{Study Design}

The study design applied is community-based unmatched case-referent study.

\section{Study Setting and Time Frame}

The population of Moinabad mandal of Ranga Reddy District, Telangana, India was studied, between July 2016 and December 2017. Moinabad mandal, has a population of approximately 56,000, residing in nearly 13,000 households from 26 villages in the subdistrict (mandal). Among them, approximately 29,000 (52\%) are male and approximately $27,000(48 \%)$ are female. Seventy-five percent of the whole population are from general caste, $25 \%$ are from schedule caste, and none from schedule tribes.

\section{Recruitment and Enrolment}

The patients were recruited by line listing from the village of Moinabad through a door to door survey. Cases were live stroke patients. Controls were live subjects without history of stroke who are from the same neighborhood and from similar socioeconomic status as cases. Controls were not taken from the same family as the cases. For every case, one control was enrolled.

\section{Data Collection}

All the houses of Moinabad were approached by a door to door survey. Families with a history of stroke and a live stroke patient were considered for enrolment. The subject was examined by a Medical Officer in the field, who has confirmed the diagnosis clinically. Data collected included the variables-demographic details including age, gender, and educational qualification, history of stroke (previous/family), hospital visits, current medical treatment, medical reports, computed tomography scan, or magnetic resonance imaging reports where available. Physical examination included blood pressure (BP) check, blood sample collection for lipid profile evaluation, and a random blood sugar.

\section{Exclusion Criteria}

Patients who are not willing to consent, patients who are not available at the time of study, patients who have expired following stroke, patients with history suggestive of transient ischemic attack were excluded for the study.

Kelsey's sample size method for unmatched case-control study was used. ${ }^{10} \mathrm{~A}$ two-sided confidence level $(1 \alpha)$ of 95 , power (\% chance of detecting) of 80 , ratio of controls to cases of 1 , least extreme odds ratio (OR) to be detected, 1.99 , based on OR for hypertension in stroke and proportion of controls with exposure of 40 in previous studies were used as input parameters. ${ }^{6,11}$ The minimum sample size was calculated to be 136 cases and 136 controls with a total sample size of 272. Proportion of cases with exposure was derived to be 57.02 . Finally, 144 cases and 144 controls participated.

\section{Data Analysis}

Data are analyzed at two levels. At primary level, prevalence and association of various risk factors were assed using Chi-square test. To derive age and gender adjusted odds ratios (AORs) of various risk factors, binary logistic regression analysis was performed with age and gender being controlled.

\section{Operational Definitions}

We defined stoke to be "a clinical syndrome characterized by rapidly developing clinical symptoms and/or signs, and at times global, loss of cerebral function, with symptoms lasting more than 24 hours or leading to death, with no apparent 
cause other than a vascular one."12-14 Those who gave a history of hypertension or who had an elevated blood pressure of either systolic above or equal to $140 \mathrm{~mm}$ of $\mathrm{Hg}$ and or a diastolic above or equal to $90 \mathrm{~mm}$ of $\mathrm{Hg}$ as a mean of three reading were termed as hypertensives. ${ }^{15}$ Diabetics were those who had a history of diabetes mellitus or a GRBS (glucometer random blood sugar) $\geq 200 \mathrm{mg} / \mathrm{dL} .{ }^{16,17}$ Generalized obesity was termed as a body mass index (BMI) above or equal to 25 . $^{18}$

WHO STEP-wise Approach to Stroke Surveillance Manual ${ }^{19}$ was used as reference, in design and conduct of the study including anthropometry and laboratory procedures.

\section{Results}

\section{Demographic Characteristics of the Study Population}

Out of the 144 controls, 59 were women and 85 were men with a mean age of 45.69 and 47.40 , respectively. Out of 144 cases, 44 were women and 100 were men with a mean age of 60.77 and 62.49 .

Estimated crude prevalence of stroke in Moinabad mandal is found to be 257(220-300) per 1, 00,000 population. Prevalence of stroke among men is 344(280-410) per lakh men and among women it is 163(110-210) per lakh women.

A higher prevalence of stroke was seen in higher age groups, men, smokers, alcohol consumers, hypertensives, and diabetics ( $\mathbf{- T a b l e ~ 1 )}$ ). This association was tested for statistical significance by Chi-square which has revealed that age and hypertension were significantly associated with stroke patients.

\section{Binary Logistic Regression Model for Deriving AOR of Various Risk Factors \\ Modifiable Risk Factors}

After adjusting the effects of age and gender in the model, the final binary logistic regression model has shown that cases are more likely to have a total cholesterol $>200 \mathrm{mg} / \mathrm{dL}$ (AOR 2.278, 95\% confidence interval [CI]: $1.101-4.713, p=0.026)$, a systolic blood pressure $\geq 140$, (AOR 2.234, 95\% CI: 1.299-3.842, $p=0.004$ ), followed by being consumers of alcohol, (AOR 1.997 95\% CI: 1.134-3.516, $p=0.017$ ), or a smoker (AOR 1.812, 95\% CI: 0.974-3.372, $p=0.060$ ), or with a diastolic blood pressure $\geq 90$, (AOR 1.795, 95\% CI: $1.057-3.049, p=0.030$ ) or those with $\mathrm{HDL}<40 \mathrm{mg} / \mathrm{dL}$. The odds of having stroke is higher among men with waist circumference $>90 \mathrm{~cm}$ (AOR 1.333, 95\% CI: 0.686-2.588 $p=0.396)$. The odds of having stroke is faintly higher among women with waist circumference $>80 \mathrm{~cm}$ (AOR 1.055, 95\% CI: $0.331-3.369, p=0.927$ ). Obesity as measured by BMI was not identified as a risk factor in our study (- Table 2 ).

Among nonmodifiable risk factors, stroke patients, were those from higher age groups (AOR 1.971, 95\% CI: 1.6242.393, $p=0.000$ ) or having a higher risk of being male (AOR 1.331, 95\% CI: 0.774-2.291, $p=0.301$ ).

\section{Comparison of Means of Risk Factors of Cases and Controls}

The mean systolic $(138.73 \pm 19.59 \mathrm{~mm} \mathrm{Hg}$ vs. $127.43 \pm 13.05 \mathrm{~mm}$ of $\mathrm{Hg}, p=0.000)$ and diastolic $(88.26 \pm 13.81 \mathrm{~mm}$ of $\mathrm{Hg}$ vs.
$83.75 \mathrm{~mm}$ of $\mathrm{Hg}, p=0.002$ ) blood pressures were significantly higher in stoke cases compared with controls. Similarly, the means of, "mean arterial pressures," abdominal girth (inches) were significantly higher in stroke cases than controls. The means of GRBS and total cholesterol were also higher in cases than controls; however, they are not statistically significant. The mean BMI among stroke patients was a unit less compared with controls (-Table 3).

\section{Discussion}

Estimated crude prevalence of stroke in Moinabad mandal is 257 per 100, 000 people, which is significantly less than in the rural district of Gadchiroli in Maharashtra. ${ }^{20}$ Adjusted incidence rate of stroke in rural Kerala is 138 per 100,000 people according to the Trivandrum Stroke Registry ${ }^{6}$ which suggests lower prevalence in that region compared with Moinabad. Prevalence data reveal considerably lower prevalence of stroke in states such as rural West Bengal, rural Karnataka, and Kuthar Valley Kashmir.,5,21 Regional variation in stroke prevalence has also been observed in the United States where there is a defined stroke belt. ${ }^{22}$ Differences in local socioeconomic conditions, risk factors, and study methodology probably contribute to the variation in prevalence.

\section{Risk Factors for Stroke}

Age and gender trends were similar to earlier stroke studies ${ }^{23}$ with greater prevalence of stroke, hypertension, and tobacco use in older subjects ${ }^{5,6}$; and greater number of males with exposure to tobacco and alcohol consumption.

Hypertension was the most frequent risk factor in our study with an OR of 2.234, consistent with data from other rural and urban studies in India, ${ }^{11,24}$ the United States, ${ }^{25}$ as well as the international multicenter INTERSTROKE study. ${ }^{26}$ Reports from AIIMS, New Delhi and SCTIMST, Trivandrum also reveal hypertension as the leading risk factor in "young stroke" (stroke < 45 years). 27,28

An estimated $54 \%$ of all stroke-related deaths in low income countries ${ }^{2}$ have been linked to hypertension ${ }^{20}$ as have $40 \%$ of all stroke-related deaths in Gadchiroli district. The Earth Institute report in 2004 stated that cardiovascular disease-related death rates across all age groups and both genders are much higher in India than in Portugal and the United States. ${ }^{29}$ These observations are indicative of both urban and rural India going through phase 2 of the epidemiological transition.

The prevalence of diabetes in our study is similar to what has been observed in rural Kerala. ${ }^{6}$ With an OR of 1.6, diabetes has a weaker stroke risk association than hypertension, smoking, and alcohol consumption.

Alcohol consumption was the major stroke risk factor in our population (OR 1.997) and was also linked to $24.6 \%$ of male stroke deaths in Gadchiroli. ${ }^{7}$ Many Indian studies however did not document such a relationship. ${ }^{6,30}$ In rural Karnataka, although alcohol consumption was prevalent in $30 \%$ of the population, it did not significantly correlate with direct cardiovascular risk factors for MI or stroke outcome. ${ }^{8}$ Binge drinking increased stroke risk by an OR of 
Table 1 Frequency of demographic and modifiable risk factor variables

\begin{tabular}{|c|c|c|c|c|c|c|c|}
\hline \multirow[t]{2}{*}{ Risk factor } & \multirow[t]{2}{*}{ Exposure } & \multicolumn{2}{|c|}{ Control } & \multicolumn{2}{|c|}{ Case (Stroke) } & \multirow{2}{*}{$\begin{array}{l}\text { Total } \\
n\end{array}$} & \multirow[t]{2}{*}{$p$-Value } \\
\hline & & $n$ & $\%$ & $n$ & $\%$ & & \\
\hline \multirow[t]{2}{*}{ Age } & $<55 y$ & 93 & $76.2 \%$ & 29 & $23.8 \%$ & 122 & \multirow[t]{2}{*}{0.000} \\
\hline & $\geq 55 y$ & 51 & $30.7 \%$ & 115 & $69.3 \%$ & 166 & \\
\hline \multirow[t]{2}{*}{ Gender } & Female & 59 & 57.3 & 44 & 42.7 & 103 & \multirow[t]{2}{*}{0.065} \\
\hline & Male & 85 & 45.9 & 100 & 54.1 & 185 & \\
\hline \multirow[t]{2}{*}{ Smoking } & No & 98 & 51.9 & 91 & 48.1 & 189 & \multirow[t]{2}{*}{0.385} \\
\hline & Yes & 46 & 46.5 & 53 & 53.5 & 99 & \\
\hline \multirow[t]{2}{*}{ Alcohol } & No & 70 & 53.4 & 61 & 46.6 & 131 & \multirow[t]{2}{*}{0.287} \\
\hline & Yes & 74 & 47.1 & 83 & 52.9 & 157 & \\
\hline \multirow{2}{*}{$\begin{array}{l}\text { Hypertension } \\
\text { SBP } \geq 140 \text { mm Hg }\end{array}$} & Normotensive & 106 & 61.6 & 66 & 38.4 & 172 & \multirow[t]{2}{*}{0.000} \\
\hline & Hypertensive & 38 & 32.8 & 78 & 67.2 & 116 & \\
\hline \multirow{2}{*}{$\begin{array}{l}\text { Hypertension } \\
\text { DBP } \geq 90 \text { mm Hg }\end{array}$} & Normotensive & 83 & 61.5 & 52 & 38.5 & 135 & \multirow[t]{2}{*}{0.000} \\
\hline & Hypertensive & 61 & 39.9 & 92 & 60.1 & 153 & \\
\hline \multirow[t]{2}{*}{ Obese by BMI } & Normal BMI & 92 & 49.5 & 94 & 50.5 & 186 & \multirow[t]{2}{*}{0.805} \\
\hline & Overweight and obese & 52 & 51.0 & 50 & 49.0 & 102 & \\
\hline \multirow[t]{2}{*}{ Diabetes } & Nondiabetic & 126 & 51.2 & 120 & 48.8 & 246 & \multirow[t]{2}{*}{0.316} \\
\hline & Diabetic & 18 & 42.9 & 24 & 57.1 & 42 & \\
\hline \multicolumn{2}{|l|}{ Total } & 144 & 50.0 & 144 & 50.0 & 288 & \\
\hline
\end{tabular}

Abbreviations: BMI, body mass index; DBP, diastolic blood pressure; SBP, systolic blood pressure.

Note: Test of Significance of Association by $X$ (Odds Ratio) $)^{2}$; ( -value in italics = statistically significant).

Table 2 Binary logistic regression

\begin{tabular}{|c|c|c|c|c|}
\hline \multirow[t]{2}{*}{ Risk factor } & \multirow{2}{*}{$\begin{array}{l}\text { Adjusted odds } \\
\text { ratio }\end{array}$} & \multicolumn{2}{|c|}{$95 \% \mathrm{CI}$ for AOR } & \multirow[t]{2}{*}{$p$-Value } \\
\hline & & Lower & Upper & \\
\hline \multicolumn{5}{|l|}{ Non-modifiable risk factor } \\
\hline Gender (male vs. female) & 1.331 & 0.774 & 2.291 & 0.301 \\
\hline Age ( $\geq 55$ vs. $<55$ y) & 1.971 & 1.624 & 2.393 & 0.000 \\
\hline \multicolumn{5}{|l|}{ Modifiable risk factor } \\
\hline Smoking & 1.812 & 0.974 & 3.372 & 0.060 \\
\hline Alcohol & 1.997 & 1.134 & 3.516 & 0.017 \\
\hline Systolic blood pressure $\geq 140$ & 2.234 & 1.299 & 3.842 & 0.004 \\
\hline Diastolic blood pressure $\geq 90$ & 1.795 & 1.057 & 3.049 & 0.030 \\
\hline Obesity or overweight (BMI $\geq 25$ ) & 0.906 & 0.527 & 1.557 & 0.721 \\
\hline Waist circumference $>90 \mathrm{~cm}$ in men & 1.333 & 0.686 & 2.588 & 0.396 \\
\hline Waist circumference $>80 \mathrm{~cm}$ in women & 1.055 & 0.331 & 3.369 & 0.927 \\
\hline Diabetes (GRBS $\geq 200$ mg/dL) & 1.648 & 0.747 & 3.637 & 0.216 \\
\hline Total cholesterol >200 mg/dL & 2.278 & 1.101 & 4.713 & 0.026 \\
\hline $\mathrm{HDL}<40 \mathrm{mg} / \mathrm{dL}$ & 1.658 & 0.976 & 2.817 & 0.062 \\
\hline
\end{tabular}

Abbreviations: AOR, adjusted odds ratios; BMI, body mass index; Cl, confidence interval; GRBS, glucometer random blood sugar; HDL, high-density lipoprotein.

Note: Predictive probability for stroke; ( $p$-values in bold = statistically significant).

1.5 in the INTERSTROKE study conducted across 22 countries including India. ${ }^{26}$

Current or past history of smoking increased stroke risk by the odds of 1.81 ; high-risk association of smoking and stroke is well established by many Indian urban and rural studies with very high ORs ranging from 3.92 in $\mathrm{WB}^{31}$ to
7.8 in Kerala. ${ }^{6}$ Tobacco inhalation was a direct cardiovascular risk factor in the rural Karnataka population. ${ }^{8}$ Nearly $37 \%$ of our subjects either smoked or chewed tobacco, a number similar to the Trivandrum Rural Stroke Registry; whereas there were significantly more documented smokers (59\%) in a hospital-based case-referent study. ${ }^{28}$ 
Table 3 Comparison of means of risk factors of cases and controls

\begin{tabular}{|l|l|l|l|l|l|l|l|}
\hline Variable & \multicolumn{2}{|c|}{ Case (Stroke) } & \multicolumn{2}{c|}{ Control } & $p$-Value & \multicolumn{2}{c|}{$95 \%$ Cl of the difference } \\
\hline & Mean & SD & Mean & SD & & Lower & Upper \\
\hline BMI & 22.78 & 4.35 & 23.79 & 3.73 & 0.036 & 1.95 & 0.07 \\
\hline SBP & 138.73 & 19.59 & 127.43 & 13.05 & 0.000 & 7.44 & 15.16 \\
\hline DBP & 88.26 & 13.81 & 83.75 & 11.15 & 0.002 & 1.60 & 7.43 \\
\hline MAP & 105.06 & 13.63 & 98.21 & 10.72 & 0.000 & 4.00 & 9.69 \\
\hline ABDG & 46.83 & 21.99 & 41.83 & 15.19 & 0.025 & 0.62 & 9.39 \\
\hline GRBS & 148.66 & 94.54 & 131.36 & 78.68 & 0.093 & 2.88 & 37.47 \\
\hline TC & 171.03 & 44.19 & 165.82 & 40.01 & 0.295 & 4.57 & 14.99 \\
\hline HDL & 41.76 & 11.72 & 43.81 & 11.59 & 0.137 & 0.66 & 4.75 \\
\hline
\end{tabular}

Abbreviations: ABDG, abdominal girth in inches; BMI, body mass index; Cl, confidence interval; DBP, diastolic blood pressure; GRBS, glucometer random blood sugar; HDL, high density lipoprotein; MAP, mean arterial pressure; SBP, systolic blood pressure; SD, standard deviation; TC, total cholesterol.

Interestingly, young strokes in the AIIMS study had low exposure to smoking. ${ }^{27}$ Whether such differences in behavioral risk factors influence stroke incidence and subtypes is not known.

Obesity as measured by waist circumference rather than BMI was more prevalent in our stroke subjects compared with controls with an OR of 1.033 (female) and 1.33 (male) stroke risks. Abdominal obesity rather than BMI seemed to be a better indicator of stroke risk in other Indian and international stroke studies. ${ }^{32-34}$ Two large population-based cardiovascular risk factor studies in rural $\mathrm{AP}^{9}$ and Karnataka ${ }^{8}$ utilized high BMI as an indicator of obesity and a direct cardiovascular risk factor for stroke or MI.

Elevated serum, total cholesterol, and a low HDL were significant stroke risk factors in this study with ORs of 2.278 and 1.658 , respectively. One-third of our stroke subjects had dyslipidemia as did $26 \%$ of those in the Trivandrum Registry. ${ }^{6}$ Urban and rural differences in risk factor profiles are disappearing in epidemiological transition. It is note-worthy that unlike well-established links between dyslipidemia (lipid factors) and cardiac ischemic events, ${ }^{35}$ the impact of dyslipidemia on stroke in the Indian context requires further study.

\section{Conclusion}

To our knowledge, this is the first study to estimate the burden of stroke in rural Telangana. The high burden of stroke in rural Telangana makes it a significant public health challenge for the State. In the current study, we found that the leading modifiable risk factors for stroke were in order, total cholesterol of above $200 \mathrm{mg} / \mathrm{dL}$, systolic blood pressure above 140, alcohol consumption, smoking, diastolic blood pressure above 90, an HDL below $40 \mathrm{mg} / \mathrm{dL}$, GRBS above $200 \mathrm{mg} / \mathrm{dL}$, waist circumference above $90 \mathrm{~cm}$ in men, and $80 \mathrm{~cm}$ in women. Generalized obesity as measured by BMI was not associated with stroke, unlike central obesity as measured by waist circumference. Among nonmodifiable risk factors, age is a leading risk factor followed by male gender. The age association could be due to the fact that advances in age are accompanied by an accretion of associated risk factors. While nonmodifiable risk factors have limited potential for amendment, all modifiable factors can be targeted in the same order of priority as the ORs demonstrated in our study. The National Program is there in place to strategically target the prevention of modifiable risk factors through primary health care in India. ${ }^{36}$ We recommend including prevention protocols for stroke victims including rehabilitation services for rural populations with limited resources.

\section{Ethical Approval}

The project got clearance from IEC of Apollo Medical College, Hyderabad. Information was given to participants and voluntary consent obtained in writing. All participants were given health education on importance of periodic screening for risk factors of noncommunicable disease, timely management, and adherence to therapy.

\section{Funding}

None.

\section{Conflict of Interest}

None declared.

\section{References}

1 Feigin VL. Stroke in developing countries: can the epidemic be stopped and outcomes improved? Lancet Neurol 2007;6(2):94-97

2 Strong K, Mathers C, Bonita R. Preventing stroke: saving lives around the world. Lancet Neurol 2007;6(2):182-187

3 Pandian JD, Sudhan P. Stroke epidemiology and stroke care services in India. J Stroke 2013;15(3):128-134

4 Taylor FC, Kumar SK. Stroke in India factsheet. Available from: (Updated 2012). ResearchGate. Available at: https://www. researchgate.net/publication/264116605_Stroke_in_India_-Fact-sheet_Updated_2012. Accessed January 30, 2019

5 Razdan S, Koul RL, Motta A, Kaul S. Cerebrovascular disease in rural Kashmir, India. Stroke 1989;20(12):1691-1693

6 Sridharan SE, Unnikrishnan JP, Sukumaran S, et al. Incidence, types, risk factors, and outcome of stroke in a developing country: the Trivandrum Stroke Registry. Stroke 2009;40(4):1212-1218

7 Kalkonde YV, Deshmukh MD, Sahane V, et al. Stroke is the leading cause of death in rural Gadchiroli, India: a prospective community-based study. Stroke 2015;46(7):1764-1768

8 Norman G, George C, Krishnamurthy A, Mukherjee D. Burden of cardiovascular risk factors of a rural population in South 
India using the WHO multivariable risk prediction algorithm. Int J Med Sci Public Health 2014;3(6):764-768

9 Chow CK, Joshi R, Gottumukkala AK, et al. Rationale and design of the Rural Andhra Pradesh Cardiovascular Prevention Study (RAPCAPS): a factorial, cluster-randomized trial of 2 practical cardiovascular disease prevention strategies developed for rural Andhra Pradesh, India. Am Heart J 2009;158(3):349-355

10 OpenEpi-Sample Size for Unmatched Case-Control Studies. Available at: http://www.openepi.com/SampleSize/SSCC.htm. Accessed February 1, 2019

11 Zodpey SP, Tiwari RR, Kulkarni HR. Risk factors for haemorrhagic stroke: a case-control study. Public Health 2000;114(3):177-182

12 Hatano S. Experience from a multicentre stroke register: a preliminary report. Bull World Health Organ 1976;54(5):541-553

13 Sacco RL, Kasner SE, Broderick JP, et al; American Heart Association Stroke Council, Council on Cardiovascular Surgery and AnesthesiaCouncil on Cardiovascular Radiology and InterventionCouncil on Cardiovascular and Stroke NursingCouncil on Epidemiology and PreventionCouncil on Peripheral Vascular DiseaseCouncil on Nutrition, Physical Activity and Metabolism. An updated definition of stroke for the 21st century: a statement for healthcare professionals from the American Heart Association/American Stroke Association. Stroke 2013;44(7):2064-2089

14 Jane $\mathrm{N}$, Improving Stroke Prevention and Outcomes in Uganda: Population Survey and Hospital Based Study. Uganda: Makerere University Kampala; 2011 Available at:

15 Chobanian AV, Bakris GL, Black HR, et al; National Heart, Lung, and Blood Institute Joint National Committee on Prevention, Detection, Evaluation, and Treatment of High Blood Pressure; National High Blood Pressure Education Program Coordinating Committee. The seventh report of the Joint National Committee on Prevention, Detection, Evaluation, and Treatment of High Blood Pressure: the JNC 7 report. JAMA 2003;289(19):2560-2572

16 Dasappa H, Fathima FN, Prabhakar R, Sarin S. Prevalence of diabetes and pre-diabetes and assessments of their risk factors in urban slums of Bangalore. J Family Med Prim Care 2015;4(3):399-404

17 American Diabetes Association.. Standards of medical care in diabetes-2013. Diabetes Care 2013;36(suppl 1) :S11-S66

18 Hruby A, Hu FB. The epidemiology of obesity: a big picture. Pharmacoeconomics 2015;33(7):673-689

19 World Health Organization, WHO STEPS Stroke Manual: The WHO STEPwise Approach to Stroke Surveillance. Geneva: World Health Organization; 2006

20 Kalkonde YV, Sahane V, Deshmukh MD, Nila S, Mandava P, Bang A. High prevalence of stroke in rural Gadchiroli, India: a community-based study. Neuroepidemiology 2016;46(4):235-239

21 Dhamija RK, Mittal S, Bansal BC. Trends in clinico-epidemiological correlates of stroke in the community. J Indian Acad Clin Med 2000;5:27-31
22 Liao Y, Greenlund KJ, Croft JB, Keenan NL, Giles WH. Factors explaining excess stroke prevalence in the US Stroke Belt. Stroke 2009;40(10):3336-3341

23 Appelros P, Stegmayr B, Terént A. Sex differences in stroke epidemiology: a systematic review. Stroke 2009;40(4):1082-1090

24 Salaam A. Epidemiology of neurological disorders in Kashmir. J Health Adm 2002;13-14:15-24

25 American Heart Association, Heart Disease and Stroke Statistics. Dallas: AHA; 2008

26 O’Donnell MJ, Xavier D, Liu L, et al; INTERSTROKE investigators. Risk factors for ischaemic and intracerebral haemorrhagic stroke in 22 countries (the INTERSTROKE study): a case-control study. Lancet 2010;376(9735) :112-123

27 Dash D, Bhashin A, Pandit AK, et al. Risk factors and etiologies of ischemic strokes in young patients: a tertiary hospital study in north India. J Stroke 2014;16(3):173-177

28 Lipska K, Sylaja PN, Sarma PS, et al. Risk factors for acute ischaemic stroke in young adults in South India. J Neurol Neurosurg Psychiatry 2007;78(9):959-963

29 Leeder SR, Raymond S, A Race Against Time: The Challenge of Cardiovascular Disease in Developing Countries. New York, NY: Trustees of Columbia University; 2004

30 Das SK, Banerjee TK, Biswas A, et al. A prospective community-based study of stroke in Kolkata, India. Stroke 2007;38(3):906-910

31 Das SK, Banerjee TK. Stroke: Indian scenario. Circulation 2008;118(25):2719-2724

32 Thankappan KR, Shah B, Mathur P, et al. Risk factor profile for chronic non-communicable diseases: results of a community-based study in Kerala, India. Indian J Med Res 2010;131:53-63

33 Larsson B, Svärdsudd K, Welin L, Wilhelmsen L, Björntorp P, Tibblin G. Abdominal adipose tissue distribution, obesity, and risk of cardiovascular disease and death: 13 year follow up of participants in the study of men born in 1913. Br Med J (Clin Res Ed) 1984;288(6428):1401-1404

34 Lapidus L, Bengtsson C, Larsson B, Pennert K, Rybo E, Sjöström L. Distribution of adipose tissue and risk of cardiovascular disease and death: a 12 year follow up of participants in the population study of women in Gothenburg, Sweden. Br Med J (Clin Res Ed) 1984;289(6454):1257-1261

35 Pikula A, Beiser AS, Wang J, et al. Lipid and lipoprotein measurements and the risk of ischemic vascular events: Framingham study. Neurology 2015;84(5):472-479

36 Training Module for Medical Officers for Prevention, Control and Population Level Screening of Hypertension, Diabetes and Common Cancer (Oral, Breast \& Cervical), National Centre for Disease Control Directorate General of Health Services Ministry of Health and Family Welfare, GOI 22Sham Nath Marg, New Delhi-110054, India, 2017 